\title{
DEBER DE PREVENCIÓN DEL ESTADO, FUNDAMENTALMENTE EN CONTEXTO PANDÉMICO
}

\author{
THE STATE'S DUTY OF PREVENTION, \\ FUNDAMENTALLY IN A PANDEMIC CONTEXT
}

\section{María Yanina Gázquez ${ }^{1}$}

DOI: https://doi.org/10.37767/2591-3476(2021)18

\section{Comentario a}

Bustos, Vilma Del Valle c/ Provincia de Córdoba - Amparo (Ley 4915)

Cámara Contenciosa Administrativa de $3^{\circ}$ Nominación Poder Judicial de la Provincia de Córdoba

\author{
Disponible en \\ https://bit.ly/3BhQ1w1
}

\section{RESUMEN:}

La Cámara en lo Contencioso Administrativo de $3^{\circ}$ Nominación de la ciudad de Córdoba no hizo lugar a una medida cautelar planteada por una psicóloga que trabaja en un centro de atención primaria de la salud (CAPS). La profesional solicitaba, entre otras cosas, que el Estado provincial se abstenga de obligarla a prestar servicio y que el tribunal la autorice a no concurrir a su lugar de trabajo, sin afectación de ingresos, hasta tanto la Provincia entregue los equipos de protección personal y garantice, en su lugar de tareas, las recomendaciones de bioseguridad para evitar el contagio de coronavirus COVID-19.

\section{ABSTRACT}

The Chamber in Administrative Litigation of the 3rd Nomination of the city of Córdoba did not accept a precautionary measure raised by a psychologist who works in a primary health care center (CAPS). The professional requested, among other things, that the provincial State refrain from forcing her to provide service and that the court authorize her not to attend her workplace, without affecting income, until the Province delivers the personal protection equipment and ensure, instead of tasks, the biosecurity recommendations to avoid the spread of coronavirus COVID-19. 
PALABRAS CLAVE: Acción de amparo; derecho a la salud; contexto pandémico; medidas de seguridad laboral; función preventiva del Estado.

KEY WORDS: protection; right to health; pandemic context; occupational safety measures; preventive function of the State.

\section{Introducción}

Un miembro de sanidad de la provincia de Córdoba, interpuso acción de amparo por encontrarse vulnerado su derecho a la vida y a la preservación de su salud en razón de las condiciones laborales dentro del establecimiento asistencial, en contexto pandémico.

La Cámara en lo Contencioso Administrativo de $3^{\circ}$ Nominación de la ciudad de Córdoba no hace lugar a la medida cautelar solicitada por la ausencia simultánea de los requisitos del art. 484 del C.P.C.C. aplicable por remisión del art. 17 de la Ley $N^{\circ}$ 4915. Sin embargo, exhorta a la provincia a que brinde los elementos de protección necesarios para el desempeño de las funciones en las mejores condiciones de seguridad conforme los protocolos de salubridad, no solo para la actora sino para todo el personal de salud.

\section{El caso bajo análisis}

\section{Pretensión de la actora}

Vilma del Valle Bustos, personal de salud, interpone una acción de amparo ley 4915 en contra de la Provincia de Córdoba. Como medida cautelar peticiona:

- El estricto cumplimiento, en su lugar de trabajo, de las recomendaciones de bioseguridad según lo estipulado por la Organización Mundial de la Salud, los protocolos nacionales y los protocolos provinciales adoptados por el Ministerio de Salud;

- La entrega de equipos de protección personal;

- Que su empleador se abstenga de obligarla a prestar servicio, así como de aplicarle sanciones, autorizándola -el Tribunal- a no concurrir a su lugar de trabajo, sin afectación de ingresos; hasta tanto no se cumplimente y acredite lo solicitado en los puntos precedentes.

El fundamento de su pretensión radica en el derecho a la vida y a la preservación de su salud, que entiende en serio riesgo debido a la situación de emergencia sanitaria acaecida por la contingencia COVID-19; el hecho de que es licenciada en psicología y presta servicios en el CAP Ciudad de los Niños de Juárez Celman y finalmente que, a raíz de la pandemia, la provincia le asignó nuevas tareas las cuales considera que no integran su especialidad y que son altamente riesgosas por sus características y por las condiciones en que las realiza.

\section{Postura de la demandada}

La provincia, al evacuar la vista a través de un informe presentado por el Dr. Rodrigo Baena -funcionario público y médico coordinador de los CAPS provinciales-, arguye que no existe verosimilitud en el derecho reclamado por la actora. El informe mencionado va en consonancia con las políticas desplegadas por el gobierno a los fines de evitar la propagación comunitaria de la enfermedad.

\section{Análisis por parte del tribunal}

El tribunal menciona que el art. 484 del CPCC, aplicable por remisión del art. 17 de la 
Ley $N^{\circ} 4915$, establece que quien tiene un fundado motivo para temer que durante el tiempo anterior al reconocimiento judicial de su derecho, éste pudiere sufrir un perjuicio inminente o irreparable, puede solicitar las medidas que, según las circunstancias, sean aptas para asegurar provisionalmente el cumplimiento de la sentencia.

Remarca que la procedencia de toda medida cautelar exige la concurrencia simultánea de los siguientes requisitos de admisibilidad, a saber: a) la verosimilitud del derecho, b) el peligro en la demora y c) el otorgamiento de contracautela suficiente.

Concluye que en el caso de autos, la verosimilitud en el derecho invocado, el cual debe surgir prima facie de la demanda y de la prueba que sustente la pretensión, no se encuentra acreditada. Los argumentos de la actora no solo no han sido objeto de prueba sino que también han sido controvertidos por la demandada.

Asimismo, a entender del tribunal, la actora invoca denominadores comunes - que en el contexto de emergencia sanitaria declarada- deben ser afrontados por todos los ciudadanos, y en especial por quienes se encuentran exceptuados del aislamiento social, preventivo y obligatorio dispuesto por el gobierno nacional. Entre estos denominadores la actora menciona la existencia de la pandemia, la agresividad, el poder de diseminación, la facilidad de contagio, el índice de letalidad de la enfermedad y la alta exposición de contagio. Estos últimos requieren del esfuerzo y la responsabilidad individual y colectiva para adoptar las medidas preventivas de cuidado a los fines de evitar el contagio.

No obstante ello, el tribunal de mérito reconoce el legítimo derecho de la actora a que su empleador le otorgue las medidas de seguridad necesarias para que pueda trabajar en un ambiente sano y apto para minimizar las posibilidades de trasmisión del virus. Es por este motivo que el tribunal exhortó a la provincia de Córdoba para que extreme las medidas tendientes a asegurar la prestación de tareas de la actora así como de todo el personal de los establecimientos asistenciales, en condiciones de seguridad según los protocolos existentes. Ello, sin descuidar las adaptaciones necesarias según las exigencias que demande la propia dinámica del virus. Destaca que no debe olvidarse la importancia que revisten los equipos de la salud en este contexto de pandemia.

La demanda asistencial y el mayor riesgo de infección generan una sobrecarga física, mental y emocional de los trabajadores de la salud. Es responsabilidad del Estado, a través del Ministerio de Salud, ejecutar las acciones pertinentes en los centros de salud para garantizar condiciones de seguridad y salud adecuadas para el personal expuesto a este agente de riesgo biológico y mitigar su impacto físico, mental y emocional sobre quienes llevan a cabo labores asistenciales en este contexto de excepción, cuidando de este modo "a quienes nos cuidan".

En conclusión el tribunal resuelve no hacer lugar a la medida cautelar solicitada, sin costas ya que no se configuran los requisitos exigidos por el art. 484 del C.P.C.C. aplicable por remisión del art. 17 de la Ley $N^{\circ} 4915$ que harían viable la medida peticionada. Sin perjuicio de ello, exhortar a la Provincia de Córdoba, en la persona de la Máxima Autoridad del Ministerio de Salud y en la del Sr. Rodrigo Baena, Coordinador de los CAPS provinciales, para que extremen las medidas tendientes a asegurar a la actora -en particular-y a todo el personal que presta funciones en los establecimientos asistenciales -en general-, los elementos de protección necesarios para el desempeño de sus funciones 
en las mejores condiciones de seguridad, conforme los protocolos existentes al respecto y las adaptaciones que deberán efectuarse, de acuerdo a las exigencias que la propia dinámica del virus demande.

\section{El amparo}

\section{Concepto}

Podemos definir al amparo como la garantía instituida para la protección de los derechos y garantías reconocidos por la Constitución Nacional, un tratado o una ley, consistente en la acción, rápida y expedita de naturaleza constitucional, dable a favor de toda persona que, sin disponer de otro medio más idóneo, vea en forma actual o inminente lesionado, restringido, alterado o amenazado -con arbitrariedad manifiesta- un derecho o garantía personal o grupal, por un acto u omisión de autoridades públicas o privada.

Su finalidad inmediata es proteger los derechos esenciales del individuo que nacen directamente de la Constitución y de los Tratados internacionales, contra los excesos de la autoridad pública o de los particulares...2."

La acción de amparo provincial es la vía idónea para la protección efectiva del derecho a la vida y su corolario el derecho a la preservación de la salud, en función de lo dispuesto por los arts. 43 Const. Nacional y 48 Const. Provincial. En esa dirección, el Tribunal de Justicia de Córdoba sostiene que "el amparo es un proceso excepcional, utilizable en las delicadas y extremas situaciones en las que por carencia de otras vías legales aptas peligra la salvaguarda de derechos fundamentales, y exige para su apertura circunstancias muy particulares caracterizadas por la presencia de arbitrariedad o ilegalidad manifiesta que, ante la ineficacia de los procedimientos ordinarios, origina un daño concreto y grave, solo eventualmente reparable por esta vía urgente y expedita" ${ }^{\prime 3}$

Por su parte la Corte Suprema de Justicia de la Nación, a partir de los tratados internacionales con jerarquía constitucional (art. 75 inc. $22 \mathrm{CN}$ ), ha reafirmado en recientes pronunciamientos, el derecho a la preservación de la salud -comprendido dentro del derecho a la vida- y ha destacado la obligación impostergable que tiene la autoridad pública de garantizar ese derecho con acciones positivas $(. . .)^{4}$

Estas vías de reclamo son fundamentales en el marco del contexto pandémico que se nos impone. Es una herramienta que válidamente pueden utilizar quienes se encuentren incursos dentro sus presupuestos.

\section{Rol supletorio}

De la exégesis de las normas tenemos que el art. 43 de la C.N. expresa: “Toda persona puede interponer acción expedita y rápida de amparo, siempre que no exista otro medio judicial más idóneo (...)"

Por su parte el art. 48 de la Constitución de Córdoba establece: "Siempre que en forma actual o inminente se restrinjan, alteren, amenacen o lesionen con arbitrariedad o ilegalidad manifiesta, derechos o garantías reconocidas por esta Constitución o por la Constitución Nacional, y no exista otra vía pronta para evitar un grave daño, la persona afectada puede pedir el amparo de los jueces en la forma que determine la ley."

\footnotetext{
2 TSJ Sala Laboral en autos “Freytes Marcela y otros c/ IPAM- Apelación, Recurso de Casación” Sent. 84 del 13/8/97, Foro de Córdoba No40 pag.253.

3 TSJ Cba., en pleno, 15/10/1999, “Carabajal”, Sem. Jur. N 1275, T. 2000-B

4 Asociación Benghalensis y otros c/ Ministerio de Salud y Acción Social, Estado Nacional s/amparo ley 16986", del 01/06/2000, JA 2002-IV, síntesis
} 
El art. 25 de la Convención Americana sobre Derechos Humanos "Pacto de San José de Costa Rica" expresa que toda persona tiene derecho a un recurso sencillo y rápido o cualquier otro recurso efectivo ante los jueces o tribunales competentes.

Y por último el art. 1 de la ley 4915, reformado por la ley 5770 establece: “La acción de amparo será admisible contra todo acto u omisión de autoridad pública o de particulares, ya sean que actúen individual o colectivamente y como personas físicas o jurídicas que en forma actual o inminente, lesione, restrinja, afecto o amenace con ilegalidad manifiesta las libertades, derechos y garantías reconocida y acordadas por las constituciones de la Nación y de la Provincia...".

Su admisibilidad se frustra cuando la arbitrariedad o ilegalidad que se invoca no surge con total nitidez, resultando entonces ajena a ésta vía todas aquellas cuestiones que sean opinables o bien, requieran de un mayor debate y aporte probatorio, excediendo por tanto las posibilidades cognoscitivas propias de esta acción (art. 2 inc. d Ley 4915). Una decisión justa del reclamo incoado merece un análisis exhaustivo de las circunstancias fácticas que rodean al caso, los antecedentes, el marco legal establecido a la cuestión, lo cual, desborda el ámbito acotado y excepcional del amparo propuesto.

La regulación constitucional deja en claro que no existen "vías previas" al amparo ya que si concurran los requisitos de admisibilidad se le da tramite a la acción, sin requerir presentaciones previas ante la administración. Sin embargo esto no significa que cualquier reclamo se canalice por vía de amparo. Si existen otras vías paralelas más idóneas aunque no necesariamente más rápidas. Sino el resultado sería que se "ordinarizaría" la vía del amparo y por ende se terminaría desnaturalizando la garantía constitucional y ya no tendría razón de ser de la existencia del proceso contencioso administrativo ni de los juicios ordinarios. ${ }^{5}$

\section{Requisitos de admisibilidad}

Las condiciones de admisibilidad son las siguientes: actualidad de la lesión, arbitrariedad o ilegalidad manifiesta del acto lesivo, que los actos no requieran debate o prueba, inexistencia de otros recursos judiciales o administrativos previos, inexistencia de una vía judicial más idónea y que el planteo no sea extemporáneo.

Se admite su procedencia cuando el empleo de los procedimientos ordinario pudiera ocasionar un daño grave e irreparable y tornara ilusoria la resolución que en definitiva se dicte, es decir que se frustra la tutela efectiva. No basta con invocar meras conjeturas sobre su posible fracaso, o argüir razones de urgencia, comodidad y economía, ya que lo que debe demostrarse es un verdadero vacío o falencia procesal, hasta el punto de que el particular quedaría privado de justicia si no se reconocer la vía rápida del amparo en el caso concreto.

En cuanto al segundo requisito -actualidad de la lesión-, las normas mencionan aspectos del quehacer estatal (activo y/u omisivo) que dan pie al amparo: lesionar, restringir, alterar y amenazar, todos ellos en forma actual e inminente. Es decir que el daño que se pretende reparar debe ser cierto y la lesión debe ser actual, ya que el amparo no se da para juzgar hechos pasados sino presentes.

5 Cam. $3^{\circ}$ C. y Com. Cba. - Sent. No 47 del 4/5/2006 - autos - "Roa García Baltasar Luis c/ Superior Gobierno de la Provincia de Córdoba - Amparo" - Actualidad Jurídica de Córdoba - Pag. 6655/6656. 
Con relación a la calificación de arbitrariedad o ilegalidad manifiesta, el acto lesivo debe mostrar fehacientemente, en su primera apariencia, la violación grosera y ostensiblemente visible del derecho subjetivo de quien promueve el amparo.

\section{Supuestos de improcedencia}

Los distintos supuestos se encuentran contemplados en el art. $2^{\circ}$ de la ley 4915 . La aludida disposición normativa prescribe que: “La acción de amparo no será admisible cuando:

a) Existan recursos o remedios judiciales o administrativos que permitan obtener la protección del derecho o garantía constitucional de que se trata;

b) El acto impugnado emanara de un órgano del Poder Judicial o haya sido adoptado por expresa aplicación de la ley Nº 16. 970;

c) La intervención judicial compromete directa o indirectamente la regularidad, continuidad y eficacia de la prestación de un servicio público, o el desenvolvimiento de actividades esenciales del Estado;

d) La determinación de la eventual invalidez del acto requiriese una mayor amplitud de debate o de prueba o la declaración de inconstitucionalidad de leyes, decretos u ordenanzas;

e) La demanda no hubiese sido presentada dentro de los quince días hábiles a partir de la fecha en que el acto fue ejecutado o debió producirse.

Estos requisitos son los que tanto la doctrina como la jurisprudencia entienden que no deben configurarse en el caso concreto para la viabilidad del instituto. Basta que se configure uno de ellos, para que esta vía sumaria, extraordinaria, subsidiaria y excepcional, quede frustrada, debiendo los interesados -entonces- ocurrir por la vía que corresponda.

\section{Medidas cautelares en el amparo \\ 1. Introducción}

Si bien la ley 4915 no habla expresamente de la posibilidad de solicitar medidas cautelares en la acción de amparo, ello se desprende del art. 15 de la ley, en la medida que dispone la apelabilidad de las resoluciones judiciales que dispongan medidas de no innovar o de suspensión de los efectos del acto impugnado.

Más allá que el art. 15 menciona sólo dos supuestos de cautelares, tanto la doctrina como la jurisprudencia han consentido la posibilidad de disponer dentro del juicio cualquier otra medida que resulte compatible con el instituto. Es decir, en virtud del principio de subsidiariedad dispuesto por el art. 17 de la ley 4915, se ha autorizado la traba de todas las medidas cautelares previstas en los códigos aplicables. Por consiguiente, es posible solicitar medidas cautelares "innovativas" dentro de la acción.

A partir de las distintas situaciones a las que puede "enfrentarse" el amparista, se pueden distinguir tres hipótesis:

a) Supuestos en que el acto que se impugna se está ejecutando o es de inminente ejecución. En este caso se podrá solicitar una medida cautelar de no innovar o de suspensión de los efectos del acto. Cabe destacar que dichas medidas no tienen efectos retroactivos, sino que se proyectan sólo para el futuro.

b) Supuestos en los que el acto y sus efectos ya se han consumado. En este caso, lo que se busca con la cautelar es conseguir la retroacción de las cosas al estado anterior, a través de una cautelar innovativa.

c) Supuestos en que se da cuestiona una omisión. En este caso también sería una 
cautelar innovativa, pero para compeler al demandado a que realice la conducta.

\section{Requisitos de procedencia}

Para que se configuren las medidas cautelares, se debe dar cumplimiento a los requisitos genéricos, exigidos para estas figuras en cualquier juicio ordinario, y otros recaudos específicos, por ser solicitadas dentro de la acción de amparo.

Por consiguiente debe demostrarse la verosimilitud en el derecho, el peligro en la demora y debe otorgarse contracautela suficiente para responder en la medida de los daños que se pudieran provocar con la medida. Pero además, al tratarse de una cautelar dentro del juicio del amparo, el solicitante deberá demostrar la apariencia de ilegalidad o arbitrariedad del acto cuestionado y la probabilidad de que la lesión afecte un derecho constitucional. Una vez solicitada la cautelar, el tribunal deberá evaluar y valorar la solicitud, y al tratarse de derechos constitucionales en juego, deberá hacerlo con un criterio amplio

\section{Prueba}

\section{Ofrecimiento}

El ofrecimiento de toda la prueba de la que hayan de valerse el actor y el demandado, deberá efectuarse juntamente con la interposición de la demanda (art. $7^{\circ}$ Ley. 4915) o al presentarse el informe del art. $8^{\circ}$ de la misma ley. Además, la prueba instrumental no sólo deberá ofrecerse sino también acompañarse en la primera presentación judicial. Este requisito se vincula con la naturaleza sumaria de la acción de amparo y a los fines de garantizar la celeridad de la misma.

También deben indicar los demás medios de prueba que quieran utilizar. El número de testigos no puede exceder de cinco por parte y cada uno debe hacerlos comparecer a su costa, sin perjuicio del eventual uso de la fuerza pública en cosa de necesidad. No se admite la absolución de posiciones.

Por último, el art. 9 prescribe que si alguna de las partes ofreció prueba, se debe ordenar su inmediata producción, fijándose la audiencia respectiva dentro del tercer día.

La prueba es esencial en todo proceso y el amparo no es una excepción a la regla, aunque por su carácter sumario, expeditivo, ágil y célere y por la singular característica de que el acto u omisión lesivos debe ser "manifiestamente" ilegal o arbitrario, la actividad probatoria se ve notoriamente restringida y simplificada.

\section{Producción}

Del art. $9^{\circ}$ de la ley 4915 surge el principio de concentración que estipula que las pruebas sean receptadas en un solo acto, a excepción de la documental que se debe otorgar con la demanda y el informe. El plazo máximo para la producción es de seis días, por lo que solamente se podrán ofrecer los medios que por su naturaleza, permiten su producción o diligenciamiento dentro de dicho plazo. En materia de la testimonial la incomparecencia injustificada de ellos sumada a la falta de utilización de la fuerza pública provoca su caducidad automática.

Para analizar el art. mencionado ut supra, se distingue entre las pruebas que se diligencian habitualmente en audiencia (testimoniales, careos, reconocimientos), y las que se producen de otro modo (informes, pericias). En relación a las primeras, se deberá disponer su inmediata producción, sin dilación alguna, una vez ofrecidas en la demanda o 
en el informe; y las segundas, en cambio, serán decepcionadas en una audiencia fijada a tales fines.

La audiencia de la prueba tendrá lugar dentro del tercer día de producido e informe circunstanciado, o una vez vencido su plazo. Además, el art. 10 de la ley 4915 presume iure et de iure la voluntad de desistir del proceso, no así del derecho, si el actor no comparece a la audiencia, con costas.

Por último, el art. 11 in fine de la ley 4915 expresa que si existiera prueba pendiente de producción por causas ajenas a las diligencias de las partes, el juez podrá ampliar dichos términos legales por igual plazo". Es decir, que la etapa probatoria en el amparo, si hay prueba para diligenciar, tiene un plazo mínimo de tres días (art. $9^{\circ}$ de la ley 4915) y un máximo de seis días (art. 11).

\section{Carga de la prueba}

Tal como refiere Hiruela de Fernández ${ }^{6}$, “corresponde al amparista acreditar la liquidez y certidumbre del derecho que denuncia lesionado o afectado. Tiene también a su cargo la demostración de la existencia del acto u omisión lesiva, e identificar al autor de la conducta reprochada. Igualmente, deberá probar el agravio o perjuicio recibido o la amenaza respectiva".

\section{Informe circunstanciado}

El art. $8^{\circ}$ de la ley 4915 expresa: "cuando la acción fuera admisible, el juez requerirá a la autoridad particular que corresponda un informe circunstanciado acerca de los antecedentes y fundamentos de la medida impugnada, el que deberá ser evacuado dentro de un plazo que no podrá exceder de tres días. La omisión del pedido de informe causa la nulidad del proceso.

El requerido deberá cumplir las cargas de ofrecer pruebas en oportunidad de contestar el informe en la forma establecida para el actor.

Producido el informe o vencido el plazo otorgado sin su presentación, no habiendo pruebas de las partes a tramitar, el tribunal dictará sentencia dentro del término establecido por el art. 11".

Es relevante destacar, que tal como lo ha sostenido el Tribunal Superior de Justicia de Córdoba ${ }^{7}$, el informe circunstanciado es una verdadera contestación de demanda, y por ello le resultan aplicables las normas adjetivas. En el mismo se debe contestar y rebatir las pretensiones de la contraparte y a su vez, plantear las defensas. Debe contener las circunstancias de tiempo, modo y lugar que provocaron o generaron la conducta que se reprocha con la acción de amparo, y relatar los hechos y el derecho que justifica tal accionar

\section{Sentencia}

El art. 11 de la ley 4915 dispone que una vez evacuado el informe circunstanciado o realizada la audiencia de prueba, el juez dicta sentencia dentro del tercer día. La jurisprudencia remarca que si no se dicta en el plazo legal, ello no genera nulidad ya que tal sanción

\footnotetext{
6 Hiruela De Fernández, María del Pilar, El amparo en la Provincia de Córdoba, Alveroni, Ediciones, Córdoba, 2002, p. 152 y ss.

7 T.S.J., Sala Civil y Comercial, in re "Scaraffía, Norma J. y otros c/Municipalidad de Villa Carlos Paz y Consorcio Edificio Marconi - amparo - recurso directo", Sent. 50, del 06/10/97
} 
no está contemplada en la ley 4915. Sin perjuicio de ello, los litigantes tienen diversos recursos procesales en caso de mora.

El art. 12 establece que la sentencia que admita la acción deberá contener: a) La mención concreta de la autoridad o del particular o particulares contra cuya resolución, acto u omisión se concede el amparo. b) La determinación precisa de la conducta a cumplir, con las especificaciones necesarias para su debida ejecución. c) El plazo para el cumplimiento de lo resuelto.

Además, debe dar cumplimiento a los requisitos formales genéricamente exigibles a toda sentencia de un juicio de conocimiento. Hay que remarcar, que la norma sólo prevé el caso de la sentencia que da lugar a la pretensión del amparista, y nada dice respecto si la misma resulta desestimatoria. Si esto último fuera el caso, la sentencia deberá reunir las condiciones de fundamentación lógica y legal exigidas por los arts. 155 de la Constitución Provincial y 326 del Código Procesal Civil y Comercial.

\section{Importancia del fallo: \\ 1. Contexto de su dictado}

El 11 de marzo de 2020 la Organización Mundial de la Salud declaró como una "pandemia" el brote de la enfermedad denominada como "coronavirus - COVID-19". En su mérito, el Poder Ejecutivo Nacional publicó el decreto N²60/2020 en el cual declaró la emergencia sanitaria en relación con el coronavirus COVID-19. Posteriormente, dictó el Decreto de Necesidad y Urgencia 297/2020 el cual dispuso el "aislamiento social preventivo y obligatorio". De dicho aislamiento estaban exceptuados, entre otros, los trabajadores de la salud por tratarse de un servicio esencial en la emergencia.

Por su parte, en el orden jurídico de la Provincia de Córdoba, se dictó la Ley 10.690, en la que se adhiere a la Emergencia Pública en materia sanitaria, declarada por el Estado Nacional en el marco de la Ley $\mathrm{N}^{\circ} 27541$, artículos 1, 64 a 85 y concordantes, el Decreto $\mathrm{N}^{\circ} 486 / 2002$ y el Decreto de Necesidad y Urgencia del Poder Ejecutivo Nacional $\mathrm{N}^{\circ}$ 260/2020. En consecuencia, la autoridad Provincial en materia relacionada al Coronavirus es el Ministerio de Salud. Es en este contexto en el cual la actora del fallo en análisis formula sus pretensiones, a la cual nos remitimos en honor a la brevedad.

\section{Deber de prevención estatal}

Es preciso señalar que el derecho a la vida y a la preservación de la salud cuentan con una intensa protección derivada de numerosos tratados internacionales (Declaración Universal de Derechos Humanos, Convención Americana sobre Derechos Humanos, Declaración Americana de los Derechos y Deberes del Hombre, Pacto Internacional de Derechos Civiles y Políticos, Pacto Internacional de Derechos Económicos, Sociales y Culturales) que poseen jerarquía constitucional (art. 75 inc. 22 de la Constitución Nacional) y constituyen un valor fundamental a resguardar, frente al cual los restantes tienen siempre carácter instrumental.

A su vez encuentra protección en el art. 42 de la Constitución Nacional. Y en idéntica línea, la Constitución Provincial de Córdoba lo consagra expresamente: considera que la salud es un bien natural y social que genera en los habitantes de la Provincia el derecho al más completo bienestar psicofísico, espiritual, ambiental y social, y coloca en cabeza del Estado Provincial el deber de garantizarlo mediante acciones y prestaciones; agre- 
gando a ello que el sistema de salud se basa en la universalidad de la cobertura, con acciones integrales de promoción, protección, recuperación y rehabilitación de la salud, e incluye el control de los riesgos biológicos sociales y ambientales de todas las personas, desde su concepción (art. 59).

El fallo en análisis, si bien no hizo lugar a la medida cautelar requerida por la actora, si exhortó a la provincia de Córdoba para que extreme las medidas tendientes a asegurar la prestación de tareas no solo de la accionante sino de todo el personal de los establecimientos asistenciales, en condiciones de seguridad según los protocolos existentes. Al hacer esto ha reconocido expresamente el deber de prevención que recae sobre el Estado, a través del Ministerio de Salud, de ejecutar las acciones pertinentes en los centros de salud para garantizar condiciones de bioseguridad para el personal expuesto a este agente de riesgo biológico.

También la resolución reconoce que la demanda asistencial genera sobrecarga física y mental de los trabajadores que integran tales equipos, sumado al mayor riesgo de contraer la infección y el consiguiente desgaste emocional. Por lo cual, el empleador debe procurar mitigar el impacto físico, mental y emocional sobre quienes llevan a cabo labores asistenciales en este contexto de excepción, cuidando de este modo "a quienes nos cuidan".

\section{Conclusiones}

En Córdoba el amparo se encuentra consagrado en el art. 48 de la Constitución provincial y regulado su procedimiento en la ley 4.915. Las discusiones acerca de la admisibilidad de dichas acciones se han visto morigeradas por la jurisprudencia, en el caso de nuestra provincia se han dado interpretaciones restrictivas respecto su admisibilidad, pero de todos modos hemos de resaltar que en esta pandemia dicha herramienta procesal ha sido de suma utilidad para quienes hicieron uso de ella para hacer valer sus derechos. Porque incluso, como en el caso de análisis, si bien la medida cautelar peticionada por la actora no prosperó, aun así logró que con su reclamo se le reconociera su derecho a un ambiente laboral sano con las medidas de seguridad pertinentes a cargo de su empleador. 


\section{REFERENCIAS BIBLIOGRÁFICAS}

- Avalos, Eduardo (2000), La acción de amparo a más de un lustro de la reforma constitucional (una visión jurisprudencial), Suplemento de Derecho Administrativo y Constitucional, año I, N² 2 .

- Bidart Campos, Germán (1969), Régimen legal y jurisprudencial del amparo, Buenos Aires, Ediar

- Buteler, Alfonso (2012), El Amparo contra actos administrativos, Abeledo Perrot.

- Carranza Torres, Luis R. (2004), Práctica del amparo, (2 edición) Cba, Alveroni.

- Hiruela de Fernández, María del Pilar (2002), El amparo en la Provincia de Córdoba, Alveroni, Ediciones, Córdoba, p. 152 y ss.

- Keselman, Sofía y Marcellino, Verónica (2001), El Amparo en la jurisprudencia del TSJ de Córdoba, Marcos Lerner Editora Córdoba.

- Sagüés, Néstor Pedro (1995), Derecho Procesal Constitucional-Acción de Amparo, Tomo

3, Astrea, pag. 182. 